\title{
CENTRO COMPLEXO E SEMOVENTE: A LINGUAGEM E A VERTIGEM CLARICE LISPECTOR
}

Americo Saraiva*

RESUMO: Este texto tem por objetivo refletir sobre aquele que julgamos ser o efeito mais saliente da escrita de Clarice Lispector. Exímia "artesã” na deformação das formações ideais que nos asfixiam, enrijecendo-nos a vertiginosa potência de existir, a escrita de Clarice tem o dom de nos devolver, estranhados, à nossa centralidade complexa e semovente. Ela estranha a si e a seu mundo para estranhar o leitor e reativar-lhe o "eu" semiótico. Reativado, este "eu" semiótico não apenas toma consciência da sua condição de centro complexo e semovente, sensível a outras formas de vida e à variedade dos afetos que as assediam, mas também torna-se, em consequência disso, capaz de evitar toda redução "naturalizadora" decorrente do exclusivismo de qualquer formação ideal em seu campo de presença.

PALAVRAS-CHAVE: Clarice Lispector; Deformação; Formação ideal; “Eu” semiótico.

\section{Introdução}

Do moderno ao contemporâneo algumas revoluções marcaram época, verdadeiros abalos sísmicos na autoimagem tranquilizadora de um estabilizado humano-narciso. O heliocentrismo de Copérnico desloca o homem do centro do universo. O evolucionismo de Darwin animaliza-o. O inconsciente freudiano tira-lhe o completo domínio da razão. A arbitrariedade do signo de Saussure consagra-o como ser de linguagem em incessante transformação.

Desse longo percurso surge um homem vulnerado em seu ego, humilhado até, mas um homem municiado pelo poder da linguagem e capaz de enfrentar o que quer que seja traduzindo a si e ao mundo em formações ideais ${ }^{1}$, que ora o aquietam, ora o desinquietam, revolucionando a sua vertigem essencial. Assim, o homem moderno deveria saber-se constituído de um centro-"eu" complexo e semovente cuja existência depende de formações ideais, puros construtos de linguagem. Adaptando a célebre formulação de Sartre, pode-se dizer que eis o homem moderno condenado à liberdade na atribuição de sentidos à vida. Mas, para desolação geral, não é isso o que necessariamente ocorre.

A mesma linguagem que alarga o domínio do humano tornando-o plástico pode restringir-lhe os horizontes. O dataísmo de Harari revela o perigo de ele, homem, ser reificado

\footnotetext{
${ }^{*}$ Doutor em Linguística pela Universidade Federal do Ceará (UFC). Professor Associado da UFC.

1 "Formação ideal" é termo tomado de empréstimo ao psicanalista brasileiro MD Magno (1999, p. 183-217) e corresponde a toda sorte de discursivização e aos construtos de linguagem dela decorrentes, gerados no domínio da religião, filosofia, ciência etc. como modo de responder, em "revirão", aos recalques: 1) originário recalque do desejo de não haver, este assimilável à pulsão de morte freudiana; 2) primário - recalque imposto pela natureza ao desejo; 3) secundário - recalque imposto pelo simbólico ao desejo quando formações ideais encontram-se naturalizadas.
} 
como produto algorítmico, de ele comportar-se como objeto programado ou sujeito apassivado sob a ação de outros sujeitos, seus programadores.

Uma tecnorreligião mais ousada está buscando cortar definitivamente o cordão umbilical humanista. Ela vislumbra um mundo que não vive em torno de desejos e experiências de quaisquer humanoides. O que poderia substituir desejos e experiências como fonte de toda autoridade e de significado? Em 2016, há um único candidato sentado na sala de espera da história, aguardando a entrevista para a admissão no emprego. O candidato é a informação. A religião mais interessante que emerge disso tudo é o dataísmo, que não venera nem deuses nem o homem - venera dados. (HARARI, 2015, p. 363)

Ao perigo dataísta hoje todos estamos expostos ou pela insuficiência ou pelo excesso de complexidade desse núcleo semovente que somos nós e que sempre estará ameaçado pelo império do não sentido ou do sentido demais, próprio de toda sorte de fanatismos (por triagem tonificante) ou niilismos (por mistura atonizante) $)^{2}$. A consciência desse perigo é fundamental para evitar-se o exclusivismo de formações ideais naturalizadas (os tais dados) que fixam a identidade de pessoas e grupos a ponto de a enrijecer ou fossilizar. Saber desse perigo é também fundamental para esquivar-se do extremo oposto, isto é, do excesso de formações ideais inviabilizador de qualquer constituição identitária.

Nos tempos atuais, gestos que evidenciem essa natureza complexa e semovente do "eu" tornam-se cada vez mais urgentes em virtude da ameaça posta pelo dataísmo. Cada vez mais, o homem precisa voltar sua atenção para a vertigem essencial que o lança num campo de presença instável, constituído como massa amorfa ${ }^{3}$, um campo de presença anterior a qualquer ação formal estabilizadora, uma instância antepredicativa, pré-discursiva, uma espécie de "eu" semiótico, que:

não se reduz ao "eu" linguístico: o "eu” semiótico é um "eu” sensível, afetado, muitas vezes atônito, quer dizer, comovido pelos êxtases que o assaltam, um "eu" mais oscilatório que identitário. (FONTANILLE; ZILBERBERG, 2001, P. 128)

Mas como voltar a atenção do homem para algo que é anterior à linguagem? Paradoxalmente, isso só se torna possível pelo exercício da própria linguagem, essa "ferramenta

\footnotetext{
${ }^{2}$ Segundo os fluxos de constituição do sentido concebidos pela Semiótica Tensiva, de Claude Zilberberg (2011), o fanatismo se configura pela operação de triagem, isto é, eliminação de valores de um dado campo de presença, acompanhada pelo crescimento da força mobilizadora dos poucos ou únicos valores que nele subsistem após o processo de triagem. O niilismo, por sua vez, implica a mistura de valores sem que nenhum ganhe saliência a ponto de mobilizar o seu sujeito.

3 "Massa amorfa" é expressão retirada do Curso de Linguística Geral, de Saussure (s/d, p. 130), e significa zona imprecisa de sentido anterior à formação pela linguagem.
} 
imperfeita"4, a um só tempo formadora e deformadora de formações ideais (ver nota 1, acima).

\section{A linguagem e a vertigem Clarice Lispector}

É aqui que a importância de alguns escritores contemporâneos salta à vista. Eles se revelam exímios "artesãos" na deformação das formações ideais que nos asfixiam, enrijecendo-nos a vertiginosa potência de existir, ao nos devolver, estranhados, à nossa centralidade complexa e semovente. Clarice Lispector é um exemplo acabado disso. Ela estranhase, isto é, não se reconhece nas formações discursivas que a cercam, para estranhar seu leitor e reativar-lhe o "eu" semiótico.

Tudo que te escrevo é tenso [...] Há muita coisa a dizer que não sei como dizer. Faltam as palavras. Mas recuso-me a inventar novas: as que existem já devem dizer o que se consegue dizer e o que é proibido. E o que é proibido eu adivinho. Se houver força. Atrás do pensamento não há palavras: é-se. Minha pintura não tem palavras: fica atrás do pensamento. Nesse terreno do é-se sou puro êxtase cristalino. É-se. Sou-me. Tu te és." (LISPECTOR, 1973, p. 27-29)

Em Água viva, Clarice dedica-se a refletir sobre o seu processo de criação verbal e explicita o que entende ser o papel da linguagem na reconstituição de uma instância que se posta "entrelinha", isto é, num aquém ou além da linguagem estabilizada em formações ideais.

Então escrever é o ato de quem tem a palavra como isca: a palavra pescando o que não é palavra. Quando essa não palavra - a entrelinha - morde a isca, alguma coisa se escreveu. Uma vez que se pescou a entrelinha, poder-se-ia com alívio jogar a palavra fora. (LISPECTOR, 1973, p. 21-22)

A palavra escrita, então, passa a ser suporte do que ela não pode suportar. Põe-se para depor-se logo em seguida, exonerando-se da cotidiana tarefa de dizer o óbvio para dizer mais e melhor o óbvio por trás do óbvio, isto é, o real lacaniano, na "entrelinha". É como se a experiência da escritura em Clarice pudesse, num golpe de estranhamento, pelo uso e abuso da linguagem, fazer-nos entrar em contato com aquela centralidade complexa e semovente, campo de constituição conflituosa de um "eu", arena onde as possibilia (os possíveis) se armam antes de tomarem forma, expondo-se, por negação, à multiplicidade de novas e inventivas formações ideais.

Trata-se de um retorno promovido pela linguagem verbal ao "eu” semiótico, instância da captação dos afetos, da experiência sensível, em que a identidade é toda ela ainda trânsito,

\footnotetext{
${ }^{4}$ Síntese expressiva do que dizemos e título do livro de Paul Henry (2013), A ferramenta imperfeita: língua, sujeito e discurso.
} 
uma espécie de vir-a-ser discursivo oscilante entre formações ideais que já não o são mais e formações ideais que não o são ainda ${ }^{5}$, isto é, um vir-a-ser que desautomatiza formações discursivas sem no entanto automatizar formações sucedâneas. Nesses termos, a palavra (ou o discurso ou a linguagem) em Clarice serve para não servir, "ferramenta imperfeita", dispensável que é na "entrelinha". Paradoxo delicioso esse, pois não há “entrelinha” sem palavras em linha, justamente o que será dispensado.

A palavra em Clarice faz-nos, assim, transitar do fechamento de um "eu" formatado pela rotina tranquilizadora dos procedimentos da aparente normalidade para a abertura de um vertiginoso campo de presença, um centro, já o dissemos, complexo e semovente, fora de padrões, ou seja, a palavra em Clarice nos restitui à franca temporalidade das oscilações afetivas: instância, indelegável, da experiência subjetiva de existir e sentir o mundo: "Eu me ultrapasso, abdicando de meu nome, e então sou o mundo.” (LISPECTOR, 1973, p. 47)

Exposta à possibilidade de novos mundos pelo sacrifício do que estava domesticado, a palavra em Clarice passa, selvagem, a franquear acesso a outros-“eu” e, consequentemente, à diversidade dos mundos que se descortinam a partir desses outros-“eu”. Porém, antes de assumir outras formas discursivas, esse centro-“eu”, complexo e semovente, experimenta, em consequência da desnomeação promovida pela "palavra jogada fora", apenas possibilidades de ser, possibilidades de constituir-se sob a ordem de formações ideais diversas. $\mathrm{O}$ leitor de Clarice sente-se lançado num espaço-tempo em formação, sente-se como "água" viva, liquefazendo-se para caber o incabível. Clarice, mais do que demonstrar ter consciência desse efeito de sua escrita sobre o leitor, confessa esforçar-se para atingi-lo: "Estou esperando a próxima frase. É questão de segundos. Falando em segundos pergunto se você aguenta que o tempo seja hoje e agora e já. Eu aguento porque comi a própria placenta." (LISPECTOR, 1973, p. 35)

Sua escrita almeja compor um aqui-agora, um meio absoluto (com princípios e fins sincopados), uma espécie de tempo-espaço da enunciação enunciante, isto é, da enunciação que se flagra como processo enunciante, fluxo constitutivo do dizer presente apenas para si mesmo, um aqui-agora expectante das evoluções do discursivo que se tece, frase a frase, para enfim fazer dizerem-se na "entrelinha” escritor e leitores. Esse espaço-tempo intervalar da palavra em Clarice instaura um desnudamento da linguagem que indicia nela, linguagem, o que lhe é mais radical, sua ação deformadora de formações ideais estabilizadas.

\footnotetext{
${ }^{5}$ Formulação que devemos a Paul Valéry, extraída de “Ce qui est (déjà) n’est pas (encore) - voici la Surprise. Ce qui n'est pas (encore) est (déjà) - voilà l'attente.” [O que (já) é não é (ainda) - eis a Surpresa. O que não é (ainda) (já) é - eis a Espera]. Cf. Cahiers, t. 2, Paris: Gallimard/La Pléiade, 1973, p. 1290.
} 
Meu tema é o instante? meu tema de vida. Procuro estar a par dele, divido-me milhares de vezes em tantas vezes quanto os instantes que decorrem, fragmentária que sou e precários os momentos - só me comprometo com a vida que nasça com o tempo e com ele cresça; só no tempo há espaço para mim. (LISPECTOR, 1973, p. 3)

Cremos poder aqui arriscar uma aproximação entre a palavra em Clarice e as postulações de Zygmunt Bauman (2000) sobre a modernidade líquida. Os dois exploram os simbolismos da água de modo semelhante. Porém, enquanto Bauman centra sua atenção nos modos de ser-líquido em formações ideais codificadas, Clarice, em Água viva, ao contrário, enfatiza-lhe a característica fundamentalmente deformadora, capaz de despertar o silêncio profundo da nossa complexidade antepredicativa, o pulsar silencioso desse centro- "eu" pré-discursivo.

A harmonia secreta da desarmonia: quero não o que está feito mas o que tortuosamente ainda se faz. Minhas desequilibradas palavras são o luxo do meu silêncio. Escrevo por acrobáticas e aéreas piruetas - escrevo por profundamente querer falar. Embora escrever só esteja me dando a grande medida do silêncio. (LISPECTOR, 1973, p. 4)

Audível apenas na "entrelinha", o silêncio pulsa no fluxo da enunciação enunciante atualizando sentidos provisórios, feitos para não tomarem forma definitiva, apenas cintilarem como promessas de significação, vislumbres do "real" (o óbvio do óbvio) por trás da realidade aparente, mostras fulgurantes do que está no âmago do instante, provas sentidas da vida sensível que se dá pela afirmação e negação simultâneas do intercurso da linguagem verbal. Para alcançar esse efeito, a palavra em Clarice precisa deixar-se surpreender em sua necessária desnecessidade.

Que música belíssima ouço no profundo de mim. É feita de traços geométricos se entrecruzando no ar. Música de câmara é sem melodia. É modo de expressar o silêncio. O que te escrevo é de câmara." (Clarice Lispector, Água viva, p. 47)

E se tenho aqui que usar-te palavras, elas têm que fazer um sentido quase que só corpóreo, estou em luta com a vibração última. Para te dizer o meu substrato, faço uma frase de palavras feitas apenas dos instantes-já. Lê então o meu invento de pura vibração sem significado senão o de cada esfuziante sílaba.” (LISPECTOR, 1973, p. 11)

Em termos semióticos, pode-se dizer que a palavra em Clarice desdobra, ou melhor, realiza o conceito de foria: etimologicamente, força de levar à frente. Ela nos reenvia ao fluxo de energia anterior à constituição dos sujeitos e dos objetos e, por isso, revela-nos a condição fundante de toda existência. Instaurar essa presença autossensível equivale a fazer vibrar, via escritura, a existência semiótica não apenas como matéria sonora, sílaba stricto sensu, mas também, e principalmente, como propriedade rítmica da expressão e do conteúdo, sílaba lato 
sensu, isto é, sílaba como fluxo de sucessivas explosões e implosões ${ }^{6}$. É no transcorrer desse fluxo, onde e quando se operam as arbitragens semióticas, sempre em vertiginoso movimento, que a palavra em Clarice quer nos lançar: "É uma tal aleluia. Aleluia, grito eu, aleluia que se confunde com o mais escuro uivo humano da dor de separação mas é grito de felicidade diabólica. Porque ninguém me prende mais.” (LISPECTOR, 1973, p. 9).

A palavra em Clarice intenciona alcançar esse ponto seminal, essa origem absoluta, esse incontornável motor de toda semiose possível, esse embrião de todos os sentidos, esse espaço-tempo prenhe de liberdade, precondição de toda temporalidade ou espacialidade de quaisquer formações ideais. Na sua dimensão sensível, esse estar aí ${ }^{7}$ arbitrante é pulsação, ritmo, sequência de aberturas e fechamentos, ponto de fabricação (cronopoiese) e destruição (cronotrofia) de tempo ${ }^{8}$ e de espaço. Em uma palavra, instante de criação de mundos e sujeitos, via linguagem. É, em suma, enunciação enunciante, instante de produção de versões linguageiras do "real", ou, nas palavras de Zilberberg, instância da enunciação, que se apresenta:

como poder de configuração complexo, oscilante, regulador, rítmico, criador de tempo quando o fazer remissivo sobrevém, concentra, nominaliza e modaliza; criador de espaço quando o fazer emissivo advém, difunde, verbaliza e "narrativiza". O "eu" aparece, no nível figural, como um lugar de interseção e arbitragem entre tempo e espaço: o tempo seria apenas a contenção do espaço assim como o espaço seria apenas o desdobramento do tempo. (ZILBERBERG, 2006, p. 137)

Alcançado esse fulcro pela desconstrução da palavra formatada é que se pode ser o mundo, ser o outro e ser os mundos desse outro. Consciente dessa centralidade complexa e semovente que constitui o homem, a palavra em Clarice cria, enfim, as condições mínimas para o exercício da empatia universal, esse estar atento às modulações do ser sensível anterior à constituição das diferentes formações ideais.

Para ilustrar o que dizemos, talvez não haja melhor exemplo do que a crônica/conto Mineirinho, publicada na revista Senhor, em 1962, em que a narradora relata, com sensibilidade e poder de reflexão aguçados, a história de um bandido chamado José Miranda Rosa, vulgo Mineirinho, assassinado com treze tiros por policiais, na cidade do Rio de Janeiro. Com as devidas escusas pela longa citação, eis o texto.

\footnotetext{
${ }^{6}$ Seguindo orientação de Hjelmslev (1975), referentemente ao isomorfismo entre os dois planos da linguagem, expressão e conteúdo, Zilberberg (2011) propõe o conceito de sílaba tensiva tomando como base a teoria da sílaba desenvolvida por Saussure (s/d). Segundo o pensador francês, haveria um paralelismo metalinguístico entre os planos da expressão e do conteúdo, e a noção de sílaba poderia ter um rendimento descritivo ampliado aplicando-se tanto a um plano quanto a outro e gerando sílabas de expressão e sílabas de conteúdo.

${ }^{7}$ Estar ai é expressão retirada de Heidegger (2005) e utilizada aqui sem o compromisso ontológico que a costuma acompanhar.

8 “Cronopoiese" e "cronotrofia" são termos cunhados por Zilberberg (2006, p. 137).
} 
É, suponho que é em mim, como um dos representantes do nós, que devo procurar por que está doendo a morte de um facínora. E por que é que mais me adianta contar os treze tiros que mataram Mineirinho do que os seus crimes. Perguntei a minha cozinheira o que pensava sobre o assunto. Vi no seu rosto a pequena convulsão de um conflito, o mal-estar de não entender o que se sente, o de precisar trair sensações contraditórias por não saber como harmonizá-las. Fatos irredutíveis, mas revolta irredutível também, a violenta compaixão da revolta. Sentir-se dividido na própria perplexidade diante de não poder esquecer que Mineirinho era perigoso e já matara demais; e no entanto nós o queríamos vivo. A cozinheira se fechou um pouco, vendo-me talvez como a justiça que se vinga. Com alguma raiva de mim, que estava mexendo na sua alma, respondeu fria: "O que eu sinto não serve para se dizer. Quem não sabe que Mineirinho era criminoso? Mas tenho certeza de que ele se salvou e já entrou no céu". Respondi-lhe que "mais do que muita gente que não matou". Por que? No entanto a primeira lei, a que protege corpo e vida insubstituíveis, é a de que não matarás. Ela é a minha maior garantia: assim não me matam, porque eu não quero morrer, e assim não me deixam matar, porque ter matado será a escuridão para mim.

Esta é a lei. Mas há alguma coisa que, se me faz ouvir o primeiro e o segundo tiro com um alívio de segurança, no terceiro me deixa alerta, no quarto desassossegada, o quinto e o sexto me cobrem de vergonha, o sétimo e o oitavo eu ouço com o coração batendo de horror, no nono e no décimo minha boca está trêmula, no décimo primeiro digo em espanto o nome de Deus, no décimo segundo chamo meu irmão. O décimo terceiro tiro me assassina — porque eu sou o outro. Porque eu quero ser o outro.

Essa justiça que vela meu sono, eu a repudio, humilhada por precisar dela. Enquanto isso durmo e falsamente me salvo. Nós, os sonsos essenciais. (LISPECTOR, 1964, p. 252)

Destaquemos o que, a nosso juízo, dá sentido a essa crônica/conto: o poder de empatia crescente que a narradora vai assumindo ao longo do relato em direção ao "nós" humanizado.

Antes de tudo, a narradora se aparta cognitivamente da "lei", fundo sobre o qual se deixam esboçar suas primeiras indagações. De fato, conforme a lógica implicativa, a lógica da "lei", não é esperado que alguém se ressinta da morte de um facínora. Mas a narradora se ressente e, para entender esse descompasso, interpela e assunta sua cozinheira à cata de saber o que lhe vai por dentro, provocando-lhe, assim, especularmente, "a pequena convulsão de um conflito", "o mal-estar de não entender o que se sente", as "sensações contraditórias", “o sentir-se dividido na própria perplexidade", ou, em nossos termos, a deformação tensionadora do universo de valor estatuído e assentado no consenso coletivo.

A cozinheira cumpre uma função mediadora, pois sabe, assim como a narradora, da "lei" que deveria reger o "nós" e que prescreve certa neutralidade objetiva com relação à morte de um assassino perverso. Apesar disso, a cozinheira, perplexa, sabe também que não deseja a morte de Mineirinho. A narradora, por sua vez, questiona a "lei" e revela-se empaticamente identificada com a cozinheira e, por tabela, com Mineirinho, depois de fazer verse, pelos olhos da cozinheira, como uma possível representante da "lei” na forma da "justiça que se vinga". 
“O que eu sinto não serve para se dizer. Quem não sabe que Mineirinho era criminoso? Mas tenho certeza de que ele se salvou e já entrou no céu". Respondilhe que "mais do que muita gente que não matou". Por que? No entanto a primeira lei, a que protege corpo e vida insubstituíveis, é a de que não matarás.

Tudo se passa como se a total empatia que nos reúne no que há de humano em "nós", promovida pela deformação da "lei" ("não matarás"), que nos protege uns dos outros ("Ela é a minha maior garantia: assim não me matam, porque eu não quero morrer, e assim não me deixam matar"), somente se instaurasse, irmanando-nos a todos, quando fôssemos capazes de romper as fronteiras erigidas pelo ego e nos instituíssemos na qualidade de centros complexos e semoventes que consentem a existência sensível de outros centros, igualmente complexos e semoventes.

Se nos for permitido colocar entre parênteses a ironia provocadora das duas últimas linhas da crônica/conto, podemos afirmar que o texto constrói um estado de autoconsciência para essa centralidade complexa e semovente, tanto no plano do narrado quanto no plano da narração. A sequência dos treze tiros desfechados contra Mineirinho caminha de par com o aumento gradual do sentimento de empatia que envolve narradora, personagens e leitor. Delineia-se, então, um percurso que vai do simples "alívio de segurança" de um "eu" submetido à "lei", passando pelo desassossego, pela vergonha e pelo horror, até chegar ao sacrifício final do "nós" na morte por assassinato.

\section{Considerações finais}

Como dizíamos mais acima, escritores da estirpe de Clarice Lispector, isto é, escritores conscientes de seu ofício de "artesãos" hábeis em devolver seus leitores, pelo exercício deformador da linguagem, a essa zona cinzenta e silenciosa da empatia plástica, a essa centralidade complexa e semovente do “eu' em formação, tornam-se cada vez mais necessários nos dias de hoje quando retrocessos de toda ordem ameaçam-nos com o retorno de um recalcado desejo de enrijecimento, fixação, fossilização da identidade de grupos e pessoas.

Pensemos no atual quadro de aguda conturbação político-ideológica, em que pessoas se digladiam assumindo antagonismos entrincheirados a partir dos quais tecem discursos supostamente críticos sobre a realidade brasileira, uns radicalmente contrários a outros, considerados a priori discursos de má-fé e, por isso, indignos de confiança, devendo ser rechaçados antes mesmo de qualquer esforço de compreensão. Nesse processo, formamse algoritmicamente grupos de discussão em que cada membro emite ponderações e/ou simples opiniões com as quais os outros membros do grupo concordam já de antemão, numa troca de informação redundante, nova apenas na aparência.

Os discursos passam então a circular de modo tautológico, confirmando e 
reforçando identidades coletivas já dadas previamente, recrudescendo formações ideais que parecem ditar os modos de sentir e de pensar para todo aquele que enuncie seu discurso a partir de uma das posições enunciativas entrincheiradas. Sabemos no entanto que, ao recusar um espaço, mínimo que seja, para o exercício da alteridade em seus domínios, todo processo discursivo se fecha num círculo vicioso de exclusiva afirmação de identidade, dando a falsa impressão de que esta goza de existência positiva e autônoma, independente do que ela não é.

Falamos dos atuais gestos ameaçadores de um achatamento do "eu", de um fechamento excessivo e apequenador da instância semiótica seminal, fonte de todo sentido, colocados em ação por obra de um moralismo reacionário antifreudiano, de um criacionismo restaurador antidarwiniano e de um terraplanismo estabilizador anticopernicano, gestos que exigem de nós combate urgente pela reativação da nossa vertigem essencial, da nossa potência de existir como centralidade complexa e semovente constitutiva de um campo de presença aberto para a experiência com a alteridade. No momento atual da história brasileira, estamos, mais do que nunca, precisados de Clarice.

\section{COMPLEX AND SEMOVENT CENTER: THE LANGUAGE AND THE VERTIGO CLARICE LISPECTOR}

ABSTRACT: This text aims to reflect on what we think the central effect of Clarice Lispector's writing is. A master in the deformation of ideal formations that asphyxiate us, stiffening us with the vertiginous power of existing, Clarice's writing has the gift of returning us, as strangers, to our complex and self-moving centrality. She becomes foreign to herself and to her own world to surprise her reader and reactivate the semiotic "I". Reactivated, this semiotic "I" is not only aware of its condition as a complex and self-moving centrality, sensitive to other forms of life and to the variety of affections that surround them, but also, as a result, it is able to avoid any "Naturalizing" reduction resulting from the exclusivity of any ideal formation in its field of presence.

KEYWORDS: Clarice Lispector; Deformation; Ideal formation; Semiotic "I".

\section{REFERÊNCIAS}

BAUMAN, Zygmunt. Modernidade líquida. Rio de Janeiro: Jorge Zahar Editor, 2000.

FONTANILLE, Jacques; ZILBERBERG, Claude. Tensão e significação. São Paulo: Discurso Editorial: Humanitas/FFLCH/USP, 2001.

HARARI, Yoval Noah. Homo deus: uma breve história do amanhã. São Paulo: Companhia das Letras, 2015.

HENRY, Paul. A ferramenta imperfeita: língua, sujeito e discurso. Campinas: Editora Unicamp, 1992.

HEIDEGGER, Martin. Ser e tempo: tomos I e II. Petrópolis: Vozes, 1986.

HJELMSLEV, Louis. Prolegômenos a uma teoria da linguagem. São Paulo: Perspectiva, 1975.

LISPECTOR, Clarice. A legião estrangeira. Rio de Janeiro: Editora do Autor, 1964. 
. Água viva. Rio de Janeiro: Editora Rocco, 1973.

MD MAGNO. In: DANTAS, Rosane Araujo; ALONSO, Aristides. Pensamento original made in Brazil. Rio de Janeiro: Oficina do autor/Estudos transitivos do contemporâneo. 1999.

SAUSSURE, Ferdinand de. Curso de linguística geral. São Paulo: Cultrix, s/d.

VALÉRY, Paul. Cabiers I. Paris: Gallimard/Bibliotèque de la Pléiade, 1973.

ZILBERBERG, Claude. Rąão e poética do sentido. São Paulo: EDUSP, 2006. Elementos de semiótica tensiva. São Paulo: Ateliê Editorial, 2011.

Recebido em: 19/09/2012.

Aprovado em: 31/12/2020. 